\title{
Características Agronômicas, Massa de Forragem e Valor Nutritivo de Brachiaria decumbens em Sistema Silvipastoril
}

\author{
Carlos Renato Tavares Castro(1), Domingos Sávio Campos Paciullo(1), Carlos Augusto Miranda Gomide ${ }^{(1)}$, \\ Marcelo Dias Müller ${ }^{(1)}$ e Éder Ribeiro Nascimento $\mathrm{Jr}^{(1)}$
}

(1) Embrapa Gado de Leite, Rua Eugênio do Nascimento, 610, Dom Bosco, CEP 36038-330, Juiz de Fora-MG. E-mails: castro@cnpgl.embrapa.br; domingos@cnpgl.embrapa.br; gomide@cnpgl.embrapa.br; muller@cnpgl.embrapa.br; eder@cnpgl.embrapa.br

\begin{abstract}
Resumo - Avaliaram-se os efeitos de três porcentagens de sombreamento (0,29\% e 45\%), proporcionado pelas leguminosas arbóreas Acacia angustissima, A. mangium, A. auriculiformis, Albizia lebbek e Gliricidia sepium, sobre características agronômicas, e o valor nutritivo do pasto de Brachiaria decumbens, durante o inverno, a primavera e o verão. Foi adotado o delineamento experimental de blocos casualizados, com três repetições. O sombreamento influenciou positivamente a massa de forragem, na primavera e no verão. No inverno, a maior massa de forragem foi obtida sob sol pleno. Os teores de proteína bruta aumentaram com o sombreamento, na primavera, mas não se modificaram em função das porcentagens de sombra, no inverno e no verão. Pelo produto da massa de forragem e o teor de proteína bruta, obtiveram-se as quantidades de proteína bruta por área, que foram maiores sob sombreamento mais intenso, na primavera e no verão. Os teores de fibra em detergente neutro e a digestibilidade in vitro da matéria seca não apresentaram tendência consistente com as porcentagens de sombreamento, em função da forte interação deste tratamento com a estação do ano.
\end{abstract}

Termos para indexação: Digestibilidade, fibra, proteína, sombreamento, leguminosas arbóreas.

\section{Agronomics Characteristics, Forage Mass and Nutritional Value of Brachiaria decumbens in a Silvopastoral System}

\begin{abstract}
The agronomic traits and nutritive value of Brachiaria decumbens pasture were evaluated under three shade percentages $(0.29 \%$ and $45 \%$ ), provided by leguminous trees (Acacia angustissima, A. mangium, A. auriculiformis, Albizia lebbek e Gliricidia sepium), during winter, spring and summer seasons. The experimental design was randomized blocks, with three replications. The forage mass was positively influenced by shading, in spring and summer seasons. In winter, the higher forage mass was observed in full sunlight condition. The values of crude protein increased in spring with shading, but did not vary with shade percentage in winter and summer seasons. The crude protein quantity per area, obtained by product between forage mass and crude protein concentration, was higher under more intensive shading, in spring and summer seasons. Fiber detergent neutral content and in vitro dry matter digestibility did not present consistent variation with shading, in function of the strong interaction between this variable and season of the year.
\end{abstract}

Index terms: Digestibility, fiber, protein, shading, leguminous trees.

\section{Introdução}

A arborização de pastagens, constituindo sistemas silvipastoris, tem-se mostrado uma opção técnica e economicamente viável para promover a sustentabilidade dos sistemas de produção animal a pasto. Em tais sistemas, também conhecidos como sistemas agroflorestais pecuários, as árvores proporcionam um ambiente com temperaturas mais amenas, resultando em maior conforto para os animais na pastagem. $\mathrm{O}$ componente arbóreo auxilia também no controle da erosão e contribui para a melhoria da fertilidade do solo, elevando a disponibilidade de nutrientes para as forrageiras herbáceas, melhorando o valor nutritivo da forragem produzida e, muitas vezes, aumentando a sua produção (CARVALHO; BOTREL, 2002; ALVIM et al, 2005; PACIULLO et al., 2007; SOARES et al., 2009).

As vantagens advindas do componente florestal são, sabidamente, mais acentuadas quando incluem arbustos e/ou árvores fixadoras de nitrogênio (CARVALHO; BOTREL, 2002; XAVIER et al., 2003). Entretanto, o sombreamento imposto pelo componente arbóreo pode afetar o estabelecimento e crescimento das gramíneas, em função da maior ou menor disponibilidade de radiação 
(ANDRADE et al., 2004; PACIULLO et al., 2008; SOARES et al., 2009). Os efeitos da disponibilidade de luz sobre o crescimento das plantas variam, entre outros fatores, com a tolerância da espécie forrageira à sombra e com a porcentagem de sombreamento (ANDRADE et al., 2004; GUENNI et al., 2008).

Assim, o presente trabalho objetivou avaliar o efeito de três porcentagens de sombreamento, promovido por leguminosas arbóreas, sobre a cobertura do solo, a massa de forragem, características agronômicas e alguns componentes do valor nutritivo do pasto de Brachiaria decumbens.

\section{Material e Métodos}

O experimento foi realizado no Campo Experimental de Coronel Pacheco (426 m de altitude, 21 ${ }^{\circ} 33^{\prime 2} 22^{\prime \prime} \mathrm{de}$ latitude sul e $43^{\circ} 06^{\prime} 15^{\prime \prime}$ de longitude oeste), propriedade da Embrapa Gado de Leite, em Minas Gerais, no período de junho de 2007 a fevereiro de 2008. O clima da região é do tipo Cwa (mesotérmico), conforme a classificação de Köppen; com temperatura média de $17^{\circ} \mathrm{C}$, de abril a setembro, e $24^{\circ} \mathrm{C}$, de outubro a março. Cerca de $90 \%$ da precipitação média anual, de $1.600 \mathrm{~mm}$, concentra-se nos meses de outubro a abril. O solo da área experimental é do tipo Latossolo Vermelho-Amarelo, distrófico de textura argilosa.

As avaliações foram feitas em uma pastagem de Brachiaria decumbens, originalmente estabelecida em 1982, em uma área de $7.500 \mathrm{~m}^{2}$, de topografia montanhosa, com aproximadamente $25 \%$ de declividade. Em dezembro de 1992, foram introduzidas na pastagem nove espécies exóticas de leguminosas arbóreas, a fim de se avaliar a adaptação das mesmas às condições edafoclimáticas da região. $\mathrm{O}$ plantio das mudas foi feito em covas $(50 \mathrm{~cm} \times 50 \mathrm{~cm} \times 50 \mathrm{~cm})$, previamente confeccionadas no espaçamento $10 \mathrm{~m} \times 10 \mathrm{~m}$ e adubadas com $50 \mathrm{~g}$ de calcário dolomítico, $80 \mathrm{~g}$ de fosfato de Araxá, 10 g de FTE Br-16 e 3 litros de esterco bovino curtido. A partir de 1998, algumas espécies desapareceram da área, em função da não adaptação ao local. De acordo com a disposição e sobrevivência das árvores, estabeleceram-se, na pastagem, três áreas distintas quanto à densidade arbórea. As espécies que se adaptaram às condições locais e permaneceram foram: Acacia angustissima, A. mangium, A. auriculiformis, Albizia lebbek e Gliricidia sepium.
Em abril de 2007, foram determinadas as áreas de projeção das copas das árvores, em cada uma das três densidades arbóreas. Na área de maior sobrevivência de árvores, a cobertura era de $30 \%$ em relação à área total da parcela. Em uma segunda área, de sobrevivência intermediária de árvores, a cobertura arbórea foi de $20 \%$ e, no terceiro terço da pastagem, a sobrevivência de árvores foi baixa, restando apenas dois indivíduos, que foram eliminados para se obter a intensidade zero de cobertura arbórea.

Os tratamentos consistiram de três porcentagens de sombreamento do pasto, correspondentes a $0,29 \%$ e $45 \%$ de redução da radiação fotossinteticamente ativa (coberturas arbóreas de 0,20\% e 30\%, respectivamente, em relação à área total da unidade experimental), dispostos no delineamento de blocos casualizados, com três repetições. Os blocos apresentavam área de $2.500 \mathrm{~m}^{2}$ e as unidades experimentais de $833 \mathrm{~m}^{2}$. As medições da radiação fotossinteticamente ativa foram realizadas bimensalmente, com auxílio de um ceptômetro da marca Decagon, modelo LP 80, em dias com céu limpo, e às $9 \mathrm{~h} 00,12 \mathrm{~h} 00$ e $15 \mathrm{~h} 00$, a fim de captar a variação diária de luminosidade. Em cada parcela, foram feitas 15 leituras de radiação incidente.

A altura do pasto foi obtida antes da coleta das amostras para estimativa da massa de forragem, com uma régua graduada em centímetros, por meio de dez leituras em cada parcela, considerando a distância do solo até o ponto médio de inclinação das folhas do estrato superior do dossel. Em seguida, era estimada a porcentagem de cobertura do solo, por meio de avaliações visuais, realizadas por três observadores previamente treinados. As amostragens do pasto para estimativa da massa de forragem foram realizadas a cada 35 dias, com auxílio de uma moldura metálica de área $0,5 \mathrm{~m}$ x $0,5 \mathrm{~m}$, lançada ao acaso 12 vezes em cada parcela. O corte foi realizado rente ao solo, com auxílio de um cutelo. No laboratório, as amostras foram separadas manualmente em capimbraquiária e material morto. Cada componente foi pesado e seco em estufa a $55^{\circ} \mathrm{C}$, para determinação da matéria seca. A fração de capim-braquiária, após secagem, foi moída, utilizando-se peneira com malha de $1 \mathrm{~mm}$ de abertura, em moinho tipo Willey.

Após as avaliações, realizadas em intervalos de 35 dias, a área era submetida ao pastejo por vacas mestiças não-lactantes, usadas apenas como ferramenta de corte. O período de pastejo variou entre três e cinco dias, 
conforme a época do ano, e os animais eram retirados da área experimental quando a vegetação apresentava altura média de $20 \mathrm{~cm}$ (primavera e verão). No inverno, optou-se pela retirada dos animais das parcelas quando a altura média do pasto era de $15 \mathrm{~cm}$, em função do baixo crescimento da gramínea durante o período de descanso.

As amostras de forragem, após secas e moídas, foram destinadas às determinações dos teores de proteína bruta (PB) e fibra em detergente neutro (FDN) e dos coeficientes de digestibilidade in vitro da matéria seca (DIVMS), conforme procedimentos descritos por Silva e Queiroz (2002).

Após a determinação dos teores de PB das amostras, foi estimada a quantidade de PB $\left(\mathrm{kg} \cdot \mathrm{ha}^{-1}\right)$ no pasto, em cada tratamento, por meio da multiplicação do teor médio de PB da forragem pela massa seca de forragem verde.

Os dados foram submetidos à análise de variância, usando o aplicativo estatístico SAS (1990), considerando o subprocedimento de medidas repetidas no tempo, em que as porcentagens de coberturas arbóreas foram estudadas nas parcelas e nas estações do ano (inverno, primavera e verão), com as medidas repetidas no tempo. As médias foram comparadas pelo teste de Tukey, a 5\% de probabilidade.

\section{Resultados e Discussão}

A altura do pasto variou $(\mathrm{P}<0,05)$ conforme a interação porcentagem de sombreamento $\mathrm{x}$ estação do ano. No inverno, as alturas do pasto submetido às três condições de sombreamento foram semelhantes (Tabela 1). Na primavera, a altura foi menor na condição de sol pleno quando comparada aos valores obtidos sob sombreamento, e no verão, as alturas foram diferentes conforme a porcentagem de sombreamento, sendo o menor valor observado no sol pleno e o maior sob sombreamento mais intenso. $\mathrm{O}$ aumento da altura com o sombreamento está em consonância com os resultados obtidos em outros estudos (CASTRO et al., 1999; ALVIM et al., 2005; PACIULLO et al., 2008) e parece ser uma tendência geral em plantas cultivadas à sombra, estratégia comum de se compensar a redução de luminosidade (SAMARAKOON et al., 1990, CASTRO et al., 1999). O chamado estiolamento de plantas submetidas ao sombreamento é um mecanismo pelo qual a planta busca luz pela elevação de suas folhas no dossel. Em gramíneas, tal mecanismo permite, ainda, melhor distribuição da radiação ao longo do perfil do dossel (MELLO; PEDREIRA, 2004; GOMIDE et al., 2007).

A massa de forragem foi influenciada $(\mathrm{P}<0,05)$ pela interação porcentagem de sombreamento $\mathrm{x}$ estação do ano. Os valores foram maiores no verão, intermediários na primavera e menores no inverno, independentemente da porcentagem de sombreamento (Tabela 1). Esse padrão de resposta foi influenciado pelas condições climáticas em cada estação. Assim, enquanto as elevadas precipitações pluviométricas e temperaturas incidentes no verão favoreceram o crescimento do pasto, a escassez de chuvas e a ocorrência de temperaturas inferiores a $15^{\circ} \mathrm{C}$ no inverno limitaram a produção de forragem.

Tabela 1. Altura do relvado e massa seca de forragem verde em pastagens de $B$. decumbens, conforme a porcentagem de sombreamento e a estação do ano.

\begin{tabular}{lccc}
\hline \multirow{2}{*}{$\begin{array}{l}\text { Estação } \\
\text { do ano }\end{array}$} & \multicolumn{3}{c}{ Sombreamento (\%) } \\
\cline { 2 - 4 } & $\mathbf{0}$ & $\mathbf{2 9}$ & $\mathbf{4 5}$ \\
\hline \multirow{3}{*}{ Inverno } & $22,4 \mathrm{Ac}$ & $23,8 \mathrm{Ac}$ & $24,6 \mathrm{Ac}$ \\
Primavera & $28,3 \mathrm{Bb}$ & $39,2 \mathrm{Ab}$ & $42,5 \mathrm{Ab}$ \\
Verão & $33,9 \mathrm{Ca}$ & $53,0 \mathrm{Ba}$ & $72,1 \mathrm{Aa}$ \\
\hline \multirow{3}{*}{$\mathrm{Massa}$ seca de forragem verde $(\mathrm{kg} / \mathrm{ha})$} \\
Inverno & $357 \mathrm{Ac}$ & $344 \mathrm{Ac}$ & $184 \mathrm{Bc}$ \\
Primavera & $1.187 \mathrm{Bb}$ & $1.640 \mathrm{Ab}$ & $1.933 \mathrm{Ab}$ \\
Verão & $2.003 \mathrm{Ca}$ & $2.463 \mathrm{Ba}$ & $4.345 \mathrm{Aa}$ \\
\hline
\end{tabular}

Médias seguidas de letras diferentes, maiúsculas nas linhas e minúsculas nas colunas, diferem pelo teste Tukey a $5 \%$ de probabilidade.

No inverno, a massa de forragem foi maior sob condições de sol pleno e de $29 \%$ de sombreamento, e menor no sombreamento mais intenso (Tabela 1). Em parte, tal resultado contrasta com a hipótese de que o crescimento do pasto poderia ser favorecido na época seca do ano, sob sombreamento, em função da redução mais lenta do teor de água no solo à sombra do que em condições de sol pleno, após um período de chuvas (WILSON, 1998). Entretanto, Paciullo et al. (2008) relataram que as condições favoráveis à manutenção da umidade do solo, proporcionadas pelo sombreamento, se manifestam principalmente durante o outono, pelo fato de que o estresse hídrico nessa estação ainda não é acentuado na região. Neste estudo, as avaliações do inverno foram realizadas nos meses de julho e agosto, quando já havia decorrido um período de aproximadamente 40 dias praticamente sem chuvas. Assim, em condições de 
acentuado estresse hídrico e maior densidade arbórea, a competição por água entre a gramínea e as árvores pode ter limitado mais drasticamente a aquisição de água pelo pasto, o que justificaria sua menor massa de forragem no inverno.

$\mathrm{Na}$ primavera, as maiores massas de forragem $(\mathrm{P}<0,05)$ foram observadas sob as duas intensidades de sombra que sob sol pleno, enquanto, durante o verão, a massa de forragem variou $(\mathrm{P}<0,05)$ diretamente com a porcentagem de sombreamento (Tabela 1). Como a restrição de radiação fotossinteticamente ativa pode diminuir as taxas fotossintéticas de forrageiras que apresentam a via fotossintética C4 (DIAS-FILHO, 2002), o sombreamento mais intenso (45\%) poderia provocar queda da massa de forragem. De fato, esse padrão tem sido observado quando o sombreamento alcança níveis superiores a 50\% da radiação a sol pleno (CASTRO et al., 1999; ANDRADE et al., 2004; PACIULLO et al., 2007; GUENNI et al., 2008). Entretanto, sombreamentos entre $35 \%$ e $45 \%$ podem não afetar o crescimento de gramíneas, desde que a forrageira seja moderadamente tolerante ao sombreamento (ANDRADE et al., 2004; PACIULLO et al., 2008). Sabe-se que a $B$. decumbens é uma espécie tolerante ao sombreamento moderado, o que decorre de ajustes morfofisiológicos, tais como aumentos da área foliar específica e da taxa de alongamento foliar, os quais possibilitam manutenção da produtividade, mesmo em condições de limitação luminosa (DIASFILHO, 2000; GUENNI et al., 2008).

Vários estudos têm demonstrado que a presença de leguminosas arbóreas em pastagens pode trazer melhorias para a fertilidade do solo, pelos aumentos dos teores de fósforo, bases trocáveis e matéria orgânica, principalmente em solos originalmente pobres em nutrientes (XAVIER et al., 2003; ALVIM et al., 2005). Assim, a maior massa de forragem sob o sombreamento de $45 \%$ esteve, provavelmente, relacionada à melhoria das condições de fertilidade do solo, em decorrência da maior densidade de leguminosas arbóreas. Xavier et al. (2003) constataram, na mesma área deste estudo, valores de cátions trocáveis (cálcio, magnésio e potássio) significativamente mais altos nas áreas de influências das árvores, do que na área de sol. Ademais, alguns estudos têm demonstrado que, em solos com baixo teor de nitrogênio, a produção de matéria seca do pasto sob sombreamento moderado, promovido por leguminosas arbóreas, é maior que aquela obtida em condições de sol pleno (WILSON, 1996; PACIULLO et al., 2007;
GUENNI et al., 2008). A serapilheira de leguminosas com capacidade de fixação biológica de nitrogênio apresenta menor relação carbono/nitrogênio (BALIEIRO et al., 2004), o que propicia maior mineralização e disponibilização de nitrogênio no solo.

Os teores de PB foram influenciados $(\mathrm{P}<0,05)$ pela interação porcentagem de sombreamento $\mathrm{x}$ estação do ano. Quanto ao efeito da estação do ano, os maiores teores foram observados na primavera, quando comparados aos obtidos nas outras duas estações (Tabela 2). Após o período de inverno, quando ocorreu alta mortalidade de perfilhos, condicionada pela escassez de água e baixas temperaturas, houve o aparecimento de novas brotações no pasto, com elevados teores de PB, favorecidos pelos aumentos graduais da precipitação e da temperatura do ar, na primavera. Com o decorrer dos ciclos de pastejo e o avanço da estação de crescimento do pasto, intensificou-se o processo de alongamento do colmo nos perfilhos e sua lignificação, o que explica o decréscimo dos teores de PB na estação do verão.

Tabela 2. Teores de proteína bruta e fibra em detergente neutro e coeficientes de digestibilidade in vitro da matéria seca de $B$. decumbens, conforme a porcentagem de sombreamento e a estação do ano.

\begin{tabular}{|c|c|c|c|}
\hline \multirow{3}{*}{$\begin{array}{l}\text { Estação } \\
\text { do ano }\end{array}$} & \multicolumn{3}{|c|}{ Sombreamento (\%) } \\
\hline & $\mathbf{0}$ & 29 & 45 \\
\hline & \multicolumn{3}{|c|}{ Proteína bruta (\% na MS) } \\
\hline Inverno & $7,7 \mathrm{Ab}$ & $8,8 \mathrm{Ab}$ & $8,3 \mathrm{Ab}$ \\
\hline Primavera & $11,2 \mathrm{Ca}$ & $13,4 \mathrm{Ba}$ & $16,5 \mathrm{Aa}$ \\
\hline \multirow[t]{2}{*}{ Verão } & $7,5 \mathrm{Ab}$ & $6,8 \mathrm{Ab}$ & $7,5 \mathrm{Ab}$ \\
\hline & \multicolumn{3}{|c|}{ Proteína bruta $\left(\mathrm{kg} \cdot \mathrm{ha}^{-1}\right)$} \\
\hline Inverno & $27,5 \mathrm{Ab}$ & $30,3 \mathrm{Ac}$ & $15,3 \mathrm{Bb}$ \\
\hline Primavera & $132,9 \mathrm{Ca}$ & $219,8 \mathrm{Ba}$ & $318,9 \mathrm{Aa}$ \\
\hline \multirow[t]{2}{*}{ Verão } & $150,2 \mathrm{Ba}$ & $167,5 \mathrm{Bb}$ & $325,8 \mathrm{Aa}$ \\
\hline & \multicolumn{3}{|c|}{ Fibra em detergente neutro ( $\%$ na MS) } \\
\hline Inverno & $72,0 \mathrm{Ab}$ & $72,2 \mathrm{Aa}$ & $72,8 \mathrm{Aab}$ \\
\hline Primavera & $74,0 \mathrm{Aa}$ & $72,4 \mathrm{ABa}$ & $72,1 \mathrm{Bb}$ \\
\hline \multirow[t]{2}{*}{ Verão } & $71,2 \mathrm{Bb}$ & $73,6 \mathrm{Aa}$ & $74,8 \mathrm{Aa}$ \\
\hline & \multicolumn{3}{|c|}{ Digestibilidade in vitro da MS (\%) } \\
\hline Inverno & $34,6 \mathrm{Bb}$ & $40,8 \mathrm{Aa}$ & $36,9 \mathrm{ABb}$ \\
\hline Primavera & $42,5 \mathrm{Ca}$ & $45,7 \mathrm{Ba}$ & $50,9 \mathrm{Aa}$ \\
\hline Verão & $45,2 \mathrm{Aa}$ & $41,0 \mathrm{ABa}$ & $39,2 \mathrm{Bb}$ \\
\hline
\end{tabular}

MS: matéria seca. Médias seguidas de letras diferentes, maiúsculas nas linhas e minúsculas nas colunas, diferem pelo teste Tukey a 5\% de probabilidade. 
O sombreamento não influenciou $(\mathrm{P}>0,05)$ o teor de PB nas avaliações feitas no inverno e no verão $(\mathrm{P}<0,05)$, no entanto, na primavera, os maiores teores foram observados sob $45 \%$ de sombreamento. O efeito positivo do sombreamento nos teores de PB está bem estabelecido na literatura, especialmente em solos com baixos teores de nitrogênio (WILSON, 1998; PACIULLO et al., 2007; SOARES et al., 2009). Entretanto, a justificativa de que os maiores teores de $\mathrm{PB}$ em plantas cultivadas à sombra poderiam resultar do pequeno efeito de diluição do nitrogênio, devido à menor quantidade de matéria seca produzida, quando comparado ao sol pleno (SOARES et al., 2009), não se aplica aos resultados ora relatados. Isto porque a massa de forragem foi maior nas áreas arborizadas, na primavera e no verão. Por outro lado, em condições de sombreamento natural, tem-se notado aumento da degradação da matéria orgânica e da reciclagem de nitrogênio no solo (WILSON, 1996). Sendo assim, boa parte do benefício da sombra nos teores de $\mathrm{PB}$ esteve associada à melhoria da fertilidade do solo (DURR; RANGEL, 2000; XAVIER et al., 2003), especialmente porque as árvores presentes na pastagem são leguminosas fixadoras de nitrogênio atmosférico.

A constatação de que houve maior aquisição de nitrogênio pelas plantas cultivadas à sombra é reforçada quando se calcula as quantidades de PB por hectare, resultante do produto entre a massa de forragem e o teor de PB (Tabela 2). Na maior porcentagem de sombreamento, as quantidades de $\mathrm{PB}$ por hectare foram $139,9 \%$ e $116,9 \%$ maiores que aquelas obtidas em condições de sol pleno, respectivamente na primavera e no verão. Treydte et al. (2008) também constataram aumento acentuado da quantidade de PB em áreas sob a influência de árvores na estação chuvosa, quando comparados aos valores obtidos em monocultivo de gramínea.

Os teores de FDN foram influenciados $(\mathrm{P}<0,05)$ pela interação porcentagem de sombreamento x estação do ano. No inverno, o teor de fibra em detergente neutro não variou com a porcentagem de sombreamento, enquanto no verão os menores teores foram observados em áreas sem árvores (Tabela 2). Possivelmente, o investimento em crescimento de colmos tenha contribuído para o aumento nos teores de fibra do capim-braquiária nas áreas sob influência das árvores. A constatação de pastos mais altos sob tais condições (Tabela 1) corrobora, de certa forma, esta hipótese, e condiz com os relatos de Paciullo et al. (2008). Os autores verificaram maiores taxas de alongamento de colmos do capim-braquiária sob sombreamento que em condições de sol pleno. Já na primavera, as concentrações de FDN foram maiores sob sol pleno, não diferindo com a estação do ano em condições de $29 \%$ de sombreamento.

A digestibilidade in vitro da matéria seca variou $(\mathrm{P}<0,05)$ com a interação porcentagem de sombreamento $\mathrm{x}$ estação do ano. Os valores de DIVMS na primavera sempre estiveram entre os maiores, o que coincidiu com os teores de PB também maiores nessa estação (Tabela 2). De forma geral, no inverno, as DIVMS foram menores que nas demais estações, com exceção dos valores obtidos em condições de $29 \%$ de sombra, os quais foram semelhantes entre estações, e sob $45 \%$ de sombra, quando foram semelhantes aos observados no verão.

No inverno, a DIVMS foi maior sob $29 \%$ de sombra e menor a sol pleno; valor intermediário foi observado sob $45 \%$ de sombreamento. De forma geral, os maiores coeficientes de DIVMS obtidos sob sombreamento condizem com relatos de Carvalho et al. (1999). Os autores também observaram que no inverno, ou em períodos de menor pluviosidade, a forragem obtida em pastagens sombreadas apresentavam digestibilidade in vitro da matéria seca superior àquela colhida em áreas fora da influência das árvores. Na primavera, a DIVMS aumentou com a porcentagem de sombreamento, enquanto no verão, o sombreamento teve influência negativa na DIVMS. Se por um lado, tanto os maiores teores de PB quanto os menores de FDN, na primavera, explicam o padrão de resposta da DIVMS nessa estação, no verão, apenas os teores de FDN se relacionaram aos coeficientes de digestibilidade. De qualquer forma, a literatura mostra certa inconsistência do efeito da sombra na digestibilidade, pois esse pode variar com diferentes fatores que influenciam na composição química da forragem. Assim, sob condições idênticas de cultivo, foram observados ausência de efeitos da sombra para $B$. brizantha e efeitos negativos para Panicum maximum (DEINUM et al., 1996). Senanayake (1995) relatou que a DIVMS de quatro gramíneas forrageiras reduziu sob sombreamento intenso ( $28 \%$ de transmissão de luz); mas aumentou sob sombra moderada (64\% de transmissão de luz), quando comparada à condição de luz solar plena.

Os percentuais de solo descoberto, material morto e forragem verde variaram $(\mathrm{P}<0,05)$ isoladamente com as percentagens de sombreamento e com as estações do ano, com exceção da ausência de significância $(\mathrm{P}>0,05)$ 
de estação do ano sobre o percentual de solo descoberto. As avaliações revelaram menores percentuais de solo descoberto e de material morto e maiores de forragem verde nas condições de $29 \%$ e $45 \%$ de sombreamento, relativamente aos valores observados sob sol pleno (Tabela 3). A maior cobertura do solo observada nas áreas arborizadas é de fundamental importância para contribuir com o controle da erosão, especialmente em áreas com topografia montanhosa, como foi o caso deste estudo.

A maior porcentagem de material morto e, consequentemente, menor de forragem verde durante o inverno, decorreu das condições climáticas desfavoráveis ao crescimento do pasto, favorecendo o aumento da senescência de perfilhos com o avanço da estação. Com o aumento da precipitação pluviométrica e da temperatura do ar, na primavera, houve o aparecimento de novos perfilhos, o que contribuiu para a elevada proporção de forragem verde no pasto. A flutuação das porcentagens de material morto e verde no pasto seguiu padrão já descrito por outros autores para a $B$. decumbens, manejada sob pastejo, na mesma região onde este estudo foi conduzido (PACIULLO et al., 2003; AROEIRA et al., 2005).

\section{Conclusões}

Sombreamentos da ordem de $29 \%$ e $45 \%$, em relação às condições de sol pleno, aumentam o percentual de cobertura do solo, a altura do pasto e a massa de forragem em pastagem de $B$. decumbens.

Leguminosas arbóreas influenciam positivamente nos teores de proteína bruta da forragem, durante a primavera. A quantidade de proteína bruta por hectare no pasto aumenta em função do sombreamento, na primavera e no verão.

Os efeitos do sombreamento nos teores de fibra em detergente neutro e na digestibilidade do pasto apresentam forte interação com a estação do ano.

Tabela 3. Porcentagens de solo descoberto (SD), material morto (MM) e forragem verde (FV) em pastagens de $B$. decumbens, conforme a porcentagem de sombreamento e a estação do ano.

\begin{tabular}{lccccccc}
\hline \multirow{2}{*}{$\begin{array}{l}\text { Variáveis } \\
(\%)\end{array}$} & \multicolumn{2}{c}{ Sombreamento (\%) } & & \multicolumn{3}{c}{ Estação do ano } \\
\cline { 2 - 4 } \cline { 6 - 8 } \cline { 6 - 8 } & $\mathbf{0}$ & $\mathbf{2 9}$ & $\mathbf{4 5}$ & & Inverno & Primavera & Verão \\
\hline SD & $20,1 \mathrm{~A}$ & $13,9 \mathrm{~B}$ & $13,1 \mathrm{~B}$ & & $12,6 \mathrm{~A}$ & $20,0 \mathrm{~A}$ & $15,6 \mathrm{~A}$ \\
$\mathrm{MM}$ & $43,0 \mathrm{~A}$ & $37,8 \mathrm{~B}$ & $34,3 \mathrm{~B}$ & & $65,2 \mathrm{~A}$ & $8,3 \mathrm{~B}$ & $14,8 \mathrm{~B}$ \\
$\mathrm{FV}$ & $36,9 \mathrm{~B}$ & $48,3 \mathrm{~A}$ & $52,6 \mathrm{~A}$ & & $22,2 \mathrm{~B}$ & $71,7 \mathrm{~A}$ & $69,6 \mathrm{~A}$ \\
\hline
\end{tabular}

Médias seguidas de letras diferentes, nas linhas, entre coberturas arbóreas ou estações do ano, diferem pelo teste de Tukey a $5 \%$ de probabilidade.

\section{Referências}

ALVIM, M. J.; CARVALHO, M. M.; XAVIER, D. F.; BOTREL, M. A. Efeito de diferentes porcentagens de sombreamento sobre uma pastagem de Brachiaria decumbens. In: XIX Reunión de la Asociación Latinoamericana de Producción Animal, Tampico. Archion Latinoamerican Production Animal. México, v. 13, 2005. p. 475-477.

ANDRADE, C. M. S.; VALENTIM, J. F.; CARNEIRO, J. C.; VAZ, F. A. Crescimento de gramíneas e leguminosas forrageiras tropicais sob sombreamento. Pesquisa Agropecuária Brasileira, v. 39, n. 3, p. 263-270, 2004.

AROEIRA, L. J. M. ; PACIULLO, D. S. C.; LOPES, F. C. F.; MORENZ, M. J. F.; SALIBA, E. S.; SILVA, J. J.; DUCATTI, C. Disponibilidade, composição bromatológica e consumo de matéria seca em pastagem consorciada de Brachiaria decumbens com Stylosanthes guianensis. Pesquisa Agropecuária Brasileira, v. 40, n. 4 p. 413-418, 2005.
BALIEIRO, F. C.; FRANCO, A. A.; PEREIRA, M. G.; CAMPELLO, E. F. C.; DIAS, L. E.; FARIA, S. M. ALVES, B. J. R. Dinâmica da serapilheira e transferência de nitrogênio ao solo, em plantios de Pseudosamanea guachapele e Eucalyptus grandis. Pesquisa Agropecuária Brasileira, v. 39, n. 6, p. 597-601, 2004.

CARVALHO, M. M.; BOTREL, M. A. Arborização de pastagens: um caminho para a sustentabilidade de sistemas de produção animal a pasto. In: EVANGELISTA, A. R.; SILVEIRA, P. J.; ABREU, J. G. (Eds.) Forragicultura e pastagens: temas em evidência. Lavras: UFLA, 2002, p. 77-108.

CARVALHO, M. M; BARROS, J. C.; XAVIER, D. F. Composición química del forraje de Brachiaria decumbens asociada con tres especies de leguminosas arbóreas. In: SEMINARIO INTERNACIONAL SOBRE SISTEMAS AGROPECUARIOS SOSTENIBLES, 6., 1999, Cali. Memórias ... Cali: CIPAV, 1999. (CD-ROM). 
CASTRO, C. T. R.; GARCIA, R.; CARVALHO, M. M.; COUTO, L. Produção forrageira de gramíneas cultivadas sob luminosidade reduzida. Revista Brasileira de Zootecnia, Viçosa, v. 28, n. 5, p. 919-927, 1999.

DEINUM, B.; SULASTRI, R. D.; SEINAB, M. H. J.;

MAASSEN, A. Effects of light intensity on growth, anatomy and forage quality of two tropical grasses (Brachiaria brizantha and Panicum maximum var. Trichoglume). Netherlands Journal of Agriculture Science, v. 44, p.111-124, 1996.

DIAS-FILHO, M. B. Growth and biomass allocation of the $\mathrm{C}_{4}$ grasses Brachiaria brizantha and $B$. humidicola under shade. Pesquisa Agropecuária Brasileira, v. 35, n. 12, p. 2335-2341, 2000.

DIAS-FILHO, M. B. Photosynthetic light response of the $\mathrm{C}_{4}$ grasses Brachiaria brizantha and B. humidicola under shade. Scientia Agricola, v. 59, n.1, p. 65-68, 2002.

DURR, P. A.; RANGEL, J. The response of Panicum maximum to a simulated subcanopy environment. 1. Soil x Shade interaction. Tropical Grasslands, v. 34, p. 110-117, 2000.

GOMIDE, C. A. M.; GOMIDE, J. A.; ALEXANDRINO, E. Características estruturais e produção de forragem em pastos de capim-mombaça submetidos a períodos de descanso. Pesquisa Agropecuária Brasileira, v. 42, n. 10, p. 1487-1494, 2007.

GUENNI, O.; SEITER, S.; FIGUEROA, R. Growth responses of three Brachiaria species to light intensity and nitrogen supply. Tropical Grasslands, v. 42, p. 75-87, 2008.

MELLO, A. C. L.; PEDREIRA, C. G. S. Respostas morfológicas do capim-tanzânia (Panicum maximum Jacq. cv. Tanzânia-1) irrigado à intensidade de desfolha sob lotação rotacionada.

Revista Brasileira de Zootecnia, v. 33, n. 2, p. 282-289, 2004.

PACIULLO, D. S. C.; AROEIRA, L. J. M.; ALVIM, M. J.; CARVALHO, M. M. Características produtivas e qualitativas de pastagem exclusiva de braquiária e consorciada com estilosantes. Pesquisa Agropecuária Brasileira, v. 38, n. 3, p. 421-426, 2003.

PACIULLO, D. S. C.; CARVALHO, C. A. B.; AROEIRA, L. J. M.; MORENZ. M. F.; LOPES, F. C. F; ROSSIELLO, R. O. P. Morfofisiologia e valor nutritivo do capim-braquiária sob sombreamento natural e a sol pleno. Pesquisa Agropecuária Brasileira, v. 42, n. 04, p. 573-579, 2007.
PACIULLO, D. S. C.; CAMPOS, N. R.; GOMIDE, C. A. M., CASTRO, C. R. T.; TAVELA, R. C.; ROSSIELlO, R. O. P. Crescimento do pasto de capim-braquiária influenciado pelo nível de sombreamento e pela a estação do ano. Pesquisa Agropecuária Brasileira, v. 43, n. 7, p. 317-323, 2008.

SAMARAKOON, S. P.; SHELTON, H. M.; WILSON, J. R. Voluntary feed intake by sheep and digestibility of shaded Stenotaphrum secundatum and Pennisetum clandestinum herbage. Journal of Agricultural Science, v.114, p.143-150, 1990.

SAS Institute, Inc. 1990. SAS/STAT User's guide, Version 6: $4^{\text {th }}$ edition. SAS Inst., Inc., Cary, NC.

SENANAYAKE, S. G. J. N. The effects of different light levels on the nutritive quality of four natural tropical grasses. Tropical Grasslands, v. 29, p. 111-114, 1995.

SILVA, J. S.; QUEIROZ, A. C. da. Análise de alimentos: métodos químicos e biológicos. 3. ed. Viçosa: UFV, 2002. 235p.

SOARES, A. B.; SARTOR, L. R.; ADAMI, P. F.; VARELLA, A. C.; FONSECA, L.; MEZZALIRA, J. C. Influência da luminosidade no comportamento de onze espécies forrageiras perenes de verão. Revista Brasileira de Zootecnia, v. 38, n. 2, p. 443-451, 2009

TREYDTE, A. C.; BEECK, F. A. L. van; LUDWIG, F.; HEITKONIN, I. M. A. Improved quality of beneath-canopy grass in South African savannas: local and seasonal variation. Journal of Vegetation Science, v. 19, n. 5, p. 663-670, 2008.

WILSON, J. R. Influence of planting four tree species on the yield and soil water status of green panic pasture in subhumid south-east Queensland. Tropical Grassland, v. 32, p. 209-220, 1998.

WILSON, J. R. Shade-stimulated growth and nitrogen uptake by pasture grasses in a subtropical environment. Australian Journal of Agriculture Research, v. 47, p. 1075-1093, 1996.

XAVIER, D. F.; CARVALHO, M. M.; ALVIM, M. J.; BOTREL, M. A. Melhoramento da fertilidade do solo em pastagem de Brachiaria decumbens associada com leguminosas arbóreas. Pasturas Tropicales, v. 25, n. 1, p. 23-26, 2003.

Recebido em 14 de maio de 2009 e aprovado em 22 de dezembro de 2009 
